\title{
Ion Chromatographic Determination of Ammonium Ion in Rain and Snow Samples
}

\author{
Yukiko DokIYA and Shinichi Bessho \\ Meteorological Research Institute, Nagamine, Tsukuba 305
}

\begin{abstract}
Ion chromatographic determination of ammonium ion using a non-suppressor-type ion chromatographic apparatus was applied to the rain and snow samples. Analytical conditions, including the concentration of eluent and the $\mathrm{pH}$ of the sample solutions, were examined to achieve the maximum sensitivity. The recovery of the amount added to the actual rain sample was found to be $95-105 \%$. Comparison with the spectrophotometric determination using indophenol was also done with sufficient reliability for a field method. Each event rain sample at Tsukuba Science City, Japan, during 1984 was used for this determination. The seasonal variation of the concentration of ammonium ion was obtained. Vertical differences of the concentration of ammonium ion in the deposition sample of 1985 were also studied using the Meteorological Observation Tower $(213 \mathrm{~m})$.
\end{abstract}

Keywords Ion chromatography, non-suppressor-type, ammonium ion, rain, snow

The usual determination of ammonium ion in rain samples has been done by spectrophotometric methods, the sensitivity of which is high. Stability of the reagents, however, is not sufficent for its use as a handy field method.

Ion chromatographic determination of the cation has been recently introduced as one of the applications of high pressure liquid chromatography. ${ }^{1-3}$ The sensitivity of ammonium ion in this method is not so high as in the spectrophotometric method. In this study, one of the most simple ion chromatographs, a non-suppressor-type, was used in order to examine the possibility of using it for field determination of ammonium in rain samples. Such use might add some useful information about the chemical components of rain samples, especially in the study of acid rain problem, when employed simultaneously with the ion chromatographic determination of anions, such as chloride, nitrate and sulfate.

\section{Experimental}

\section{Instruments}

A Wescan cation column No. 269-004 was connected to a Reactor Motor NSP(55K25GKA) of Oriental Motor Co., Ltd. A Wescan Conductivity Detector Model 213 A was used for the detection of ions.

The pump pressure was adjusted to $160 \mathrm{~kg} / \mathrm{cm}$, with the flow rate of $2.6 \mathrm{ml} / \mathrm{min}$.

Pure reagents of analytical grade were used throughout this study. Water pulified by a Milli-RQ system of Millipore Ltd. was used for the dilution of samples and reagents.

The concentration of nitrate ion was also determined by ion chromatography using a Model IC 100 of Yokogawa Hokushin Electric Co., Ltd.

\section{Samples}

Each event rain or snow sample was collected through polyethylene funnels $(30 \mathrm{~cm}$ diameter) connected to polyethylene bottles $(5 \mathrm{l})$. The funnels and bottles were washed well with detergent solution then rinsed with purified water just before the rain events. After each event, the sample solution was filtered through a Millipore filter $(0.45 \mu \mathrm{m})$ as soon as possible. The filtrate was used for ion chromatographic determination of sodium, ammonium and potassium. About 1 $\mathrm{ml}$ sample solution was injected into the sample loop of $0.1 \mathrm{ml}$, including the solution used for washing the system.

\section{Results and Discussion}

\section{Analytical conditions}

In order to find out the best analytical conditions, the effect of concentration of nitric acid as the eluent on the peak height of ammonium ion was examined. Since the pump pressure could not be changed quantitatively over a wide range, it was fixed at 160 $\mathrm{kg} / \mathrm{cm}$ in order to give a flow rate of $2.6 \mathrm{ml} / \mathrm{min}$. The relationship between the concentration of nitric acid and the peak height of ammonium ion is shown in Fig. 1. It was found that the concentrations higher than 3 $\mathrm{mM}$ gave a maximum peak height. The time required 


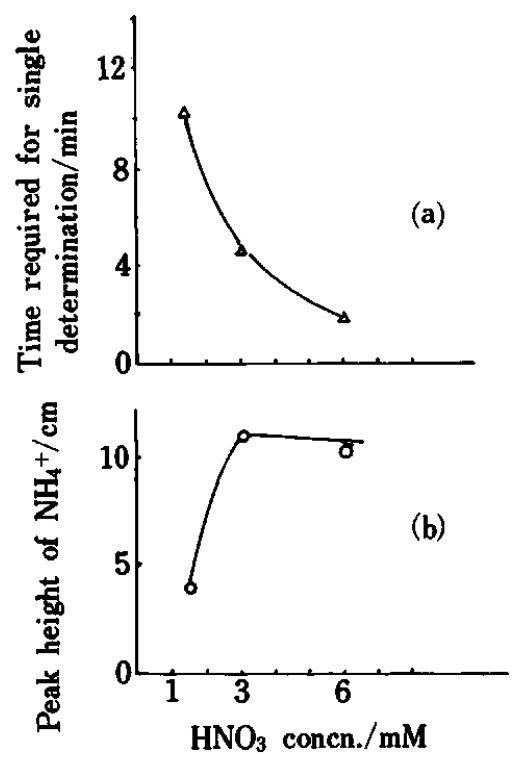

Fig. 1 Relationship between the concentration of eluent $\left(\mathrm{NO}_{3}{ }^{-}\right)$and the peak height of $\mathrm{NH}_{4}{ }^{+}$and the time required for one determination.

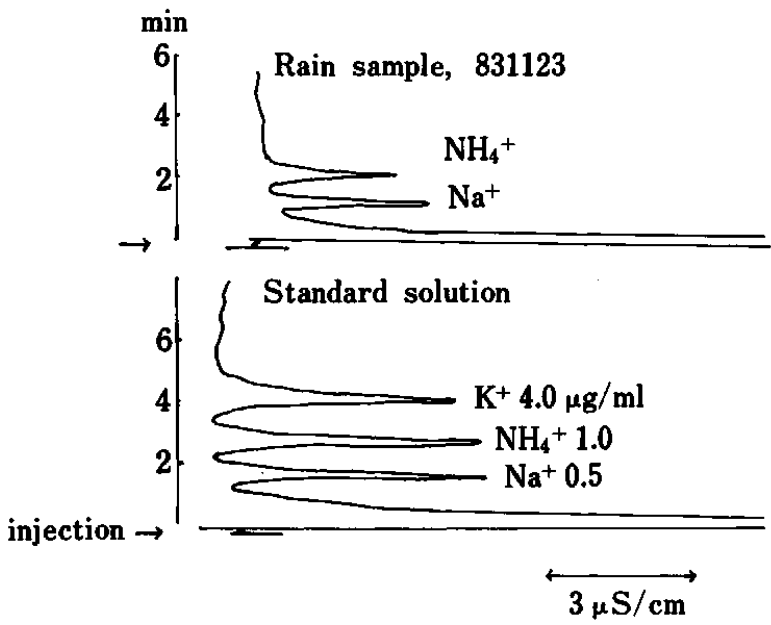

Fig. 2 Ionchromatograms of standard solution and a rain sample.

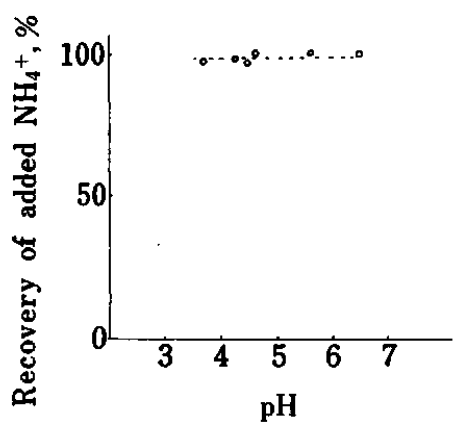

Fig. 3 Recovery of $\mathrm{NH}_{4}{ }^{+}$added to the actual rain samples. for the determination of ammonium ion is also shown in Fig. 1, as a function of nitric acid concentration. We concluded from these data and the consideration that a lower concentration is preferable for the ion chromatographic system made of SAS, that $3 \mathrm{mM}$ nitric acid should be used in the following determination.

Ion chromatograms of a standard solution and a rain sample of Nov. 23, 1983 are shown in Fig. 2. The detection limit for ammonium ion was around 0.02 $\mu \mathrm{g} / \mathrm{ml}$, giving a peak height twice as high as the background noise level.

Calibration curves were linear in the concentration range of $0.1-10 \mu \mathrm{g} / \mathrm{ml}$ in the analytical condition shown above.

The effect of the $\mathrm{pH}$ of the sample solution was examined. The $\mathrm{pH}$ of the rain and snow samples at Tsukuba ranged approximately from 3.1 to 6.7 with an average (5 years) of 4.5.4 Figure 3 shows the recovery of known amount of ammonium ion added to the actual rain samples of $\mathrm{pH} 3.6-6.5$. As seen from the figure, almost $100 \%$ recovery was obtained over the natural $\mathrm{pH}$ range.

The effect of co-existing ions on the determination of ammonium ion was also examined. Sodium and potassium ions had no significant effect up to 50 $\mu \mathrm{g} / \mathrm{ml}$ and $400 \mu \mathrm{g} / \mathrm{ml}$, respectively, but at higher concentrations of them the resolution of the peaks was not satisfactory. Calcium, magnesium, iron and zinc ions had no effect on ammonium determination up to the concentration of $100 \mu \mathrm{g} / \mathrm{ml}$, which is more than 10 times the natural concentration in rain samples.

\section{Comparison with spectrophotometric method}

Table 1 shows the results of the determination of ammonium ion by ion chromatography and by a spectrophotometric method using indophenol ${ }^{5}$ in the actual rain samples of April 1-May 28, 1985. The data obtained by ion chromatography are comparable to

Table 1 Comparison of ion chroatography and spectrophotometry for determination of ammonium ion in rain water

\begin{tabular}{cccc}
\hline Sample & $\begin{array}{c}\text { Amount of } \\
\text { precipitation/ } \\
\text { mm }\end{array}$ & \multicolumn{2}{c}{$\mathrm{NH}_{4}{ }^{+}$concentration $/ \mu \mathrm{g} \mathrm{ml}^{-1}$} \\
\cline { 3 - 4 } & Spectrophotom. Ion Chromatog. \\
\hline 850401 & 6.5 & 1.65 & 1.66 \\
850408 & 16.5 & 0.35 & 0.38 \\
850414 & 30.5 & 0.75 & 0.63 \\
850416 & 10.0 & 0.10 & 0.06 \\
850423 & 51.5 & 0.20 & 0.18 \\
850424 & 8.0 & 1.65 & 1.57 \\
850428 & 3.5 & 1.85 & 1.98 \\
850521 & 34.0 & 0.25 & 0.23 \\
850525 & 16.3 & 0.50 & 0.56 \\
850528 & 4.5 & 0.40 & 0.38 \\
weighted mean & 0.49 & 0.46 \\
\hline
\end{tabular}

a. Indophenol method. 
those obtained by spectrophotometric method, with a small variation which is tolerable in a field method.

The concentrations of sodium and potassium in these samples, obtained at the same time by ion chromatography, were also compared with those from flame emission spectrometry. The results for sodium showed a good agreement, within $5 \%$ variation. The concentration of potassium in actual rain sample was, however, usually less than $0.5 \mu \mathrm{g} / \mathrm{ml}$, which is the detection limit by ion chromatographic determination in this analytical condition. Therefore, potassium had to be determined separately by flame emission spectrometry in these samples.

\section{Preservation of samples}

One of the difficulties of determination of ammonium ion in natural samples has been the unstableness of the sample solution. In addition, the unstableness of the reagents can hardly be distinguished from that of

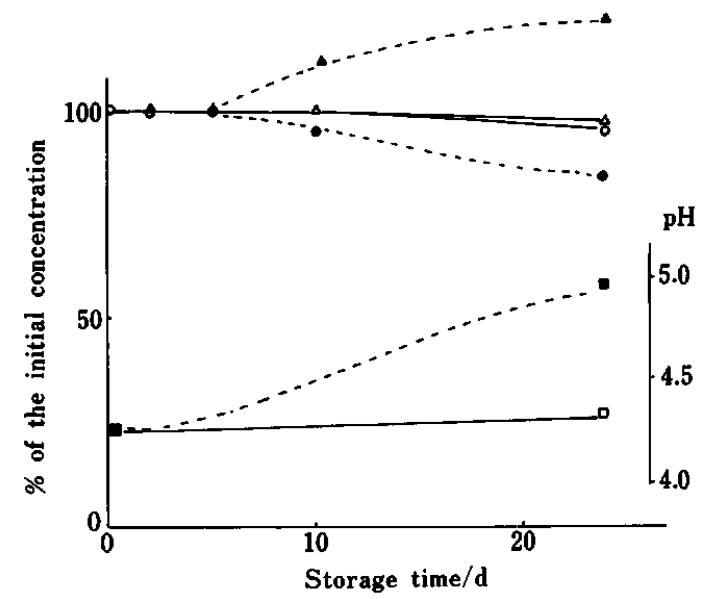

Fig. 4 Change of $\mathrm{NH}_{4}{ }^{+}$and $\mathrm{NO}_{3}{ }^{-}$in rain sample during the storage at room temperature. $\Delta, \mathrm{NH}_{4}{ }^{+}$not filtered; $\triangle$, $\mathrm{NH}_{4}{ }^{+}$filtered; $\mathrm{O}, \mathrm{NO}_{3}{ }^{-}$filtered; $\bigcirc, \mathrm{NO}_{3}{ }^{-}$not filterd. $\square, \mathrm{pH}$ unfiltered; $\square$, pH filtered.

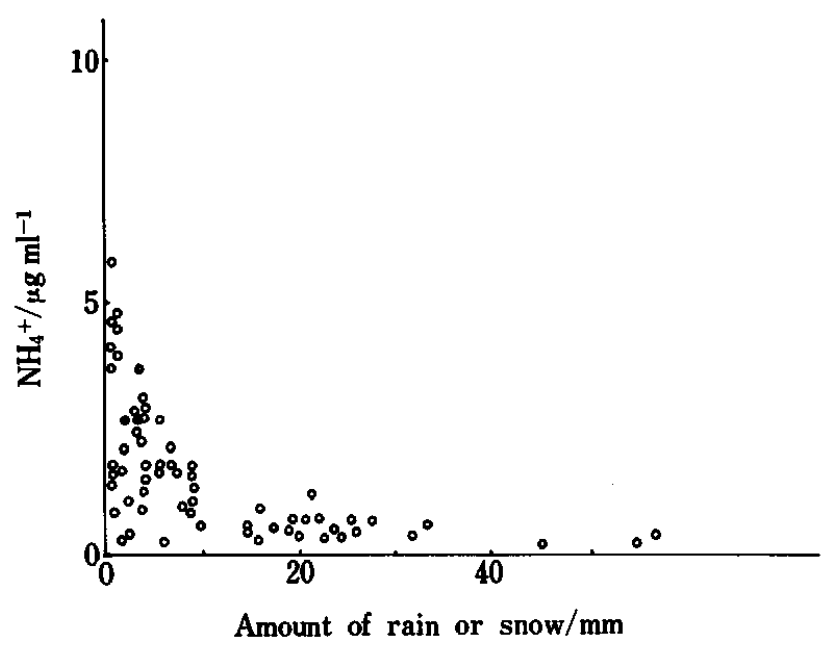

Fig. 5 Concentration of $\mathrm{NH}_{4}{ }^{+}$in the rain and snow at Tsukuba in 1984. ammonium ion in actual measurements. In this study, since the unstableness of the reagents could be neglected, the changes of ammonium ion concentration in actual rain samples could be tested.

Figure 4 shows one example of preservation test. Solid lines show the concentrations of ammonium ion and nitrate ion in filtered sample and dotted lines show those of unfiltered samples; both samples were kept at room temperature in polyethylene bottles. Filtered samples showed good stability for more than one week, while unfiltered samples showed an increase of ammonium ion and decrease of nitrate ion during one-week storage. Some unfiltered samples preserved in light became green, indicating the existence of algae or other microorganisms, which seemed to be responsible for the biological conversion of nitrate to ammonium during the storage of one week.

$$
\mathrm{NH}_{4}{ }^{+-N}
$$

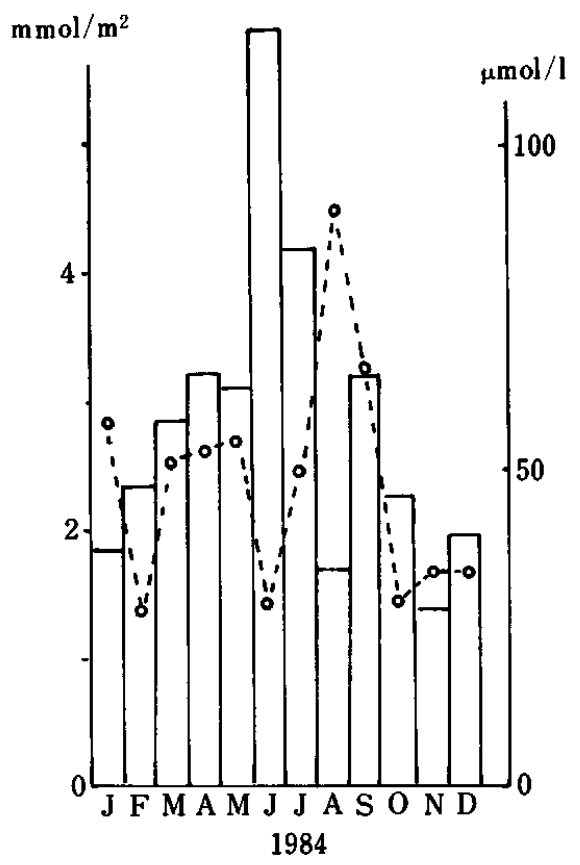

Fig. 6 Seasonal variation of concentration of $\mathrm{NH}_{4}^{+}$in the rain and snow at Tsukuba. Monthly deposition amount (column), monthly mean concentration(dotted line).

\begin{tabular}{|c|c|c|c|c|c|c|}
\hline 150 & 100 & 50 & 50 & 100 & 150 & \multirow[t]{2}{*}{$\mathbf{F}$} \\
\hline 213 & & \multicolumn{4}{|c|}{$\mathrm{K}^{+} \mathrm{Mg}^{2+}$} & \\
\hline & $\mathrm{NO}_{3}^{-}$ & $\mathrm{SO}_{4}{ }^{2-}$ & $\left|\mathrm{NH}_{4}^{+}\right|$ & & $\mathrm{H}^{+}$ & \multirow[t]{2}{*}{ pH 4.03} \\
\hline \multicolumn{6}{|c|}{$\mathrm{Na}^{+} \mathrm{Ca}^{2+}$} & \\
\hline $0.5 \mathrm{~m}$ & & & \multicolumn{3}{|c|}{$\mathrm{K}^{+} \mathrm{Mg}^{2+}$} & \multirow[b]{2}{*}{$\mathrm{pH} 4.42$} \\
\hline $\mathrm{Cl}^{-}$ & $\mathrm{NO}^{3-}$ & $\mathrm{SO}_{4}{ }^{2-}$ & $\mathrm{NH}_{4}^{+}$ & $\mathrm{H}$ & $I^{+}$ & \\
\hline
\end{tabular}

Fig. 7 Chemical composition of rain obtained at $213 \mathrm{~m}$ and near the ground. $F=\mu$ mol $\times$ valence. 
The $\mathrm{pH}$ of the solution was also measured; values are shown in Fig. 4. The unfiltered sample showed an increase of $\mathrm{pH}$ during the storage which coincided with the increase of ammonium ion.

Concentration of ammonium ion in the rain and snow at Tsukuba Science City, 1984

The concentration of ammonium ion in each event rain and snow of 1984 is plotted against the amount of rain or snow in Fig. 5. Generally, the concentration was higher when the amount was smaller. The relationship of them, however, was not a simple proportion, owing to the source strength of ammonium, the meteorological conditions and the rate of contribution of dry deposition.

Figure 6 shows the seasonal variation of deposition amount (concentration $\times$ amount of rain or snow) and the concentration of ammonium ion shown as the monthly deposition amount (column) and monthly mean concentration (dotted line). It is seen from the figure that the deposition amount was high in June and July when the amount of rain was high. On the other hand, it was low in winter when the amount of rain and snow was low. The concentration of ammonium ion was generally around $40 \mu \mathrm{g} / \mathrm{ml}$, except for the higher values in August and September. In 1984, the amount of rain and snow was extraordinally low on the Pacific side of Honshu Island, Japan, including Tsukuba. It was only $825 \mathrm{~mm} / \mathrm{y}$ compared with $1341 \mathrm{~mm} / \mathrm{y}$ at $\mathrm{Mito}^{6}$ (average for past 30 years). It was especially low in August and in September when high amounts of rain are recorded in usual years, due to typhoons. This can be one explanation for the high concentration of ammonium ion in these months. The amount of ammonium ion originating from the soil is also higher in summer than in other seasons.?
Vertical differences of $\mathrm{pH}$ in the rain and the concentration of ammonium ion

The Meteorological Observation tower $(213 \mathrm{~m})$ was utilized to get information on the vertical distribution of ammonium ion in the airborne particles and in the rain samples. Polyethylene funnels were also set at the top $(213 \mathrm{~m})$ of the tower to get the rain samples at the same time as at the observation field.

Figure 7 shows an example of difference in chemical compositions and the $\mathrm{pH}$ in the rain samples obtained at $213 \mathrm{~m}$ and at $0.5 \mathrm{~m}$ above the ground. The higher $\mathrm{pH}$ of the rain near the ground can be explained by its higher concentration of ammonium, which might have been scavenged from the airborne particles of higher ammonium concentrations near the ground. It is accepted that ammonium ion in the rain mainly originated from the soil by the activity of microorganisms. $^{7}$

\section{References}

1. "Ion Chromatographic Analyser (Model ICI 100) Application Data(II)", TI 15 ClA1-23, Yokogawa Hokushin Co., Ltd., Tokyo (1984).

2. G. Muto and K. Oikawa, "Ion Chromatography", p. 45, Kodansha-Scientific, Tokyo (1983).

3. J. S. Fritz, D. T. Gjerde and R. M. Becker, Anal. Chem., 52, 2 (1980).

4. T. Kanazawa, K. Saruhashi and Y. Miyake, Papers in Meteorol. Geophys. 35, 103 (1984).

5. Y. Miyake and Y. Kitano, "Shin-suishitsu-Kagakubunseki", p. 135, Chijinshokan, Tokyo (1976).

6. Japan Meteorological Agency, "Climatic Table of Japan" (1981).

7. E. Meszaros, "Atmospheric Chemistry", Elsevier, Amsterdam (1981). 